\title{
A systematic review and meta-analysis comparing intracorporeal anastomosis and extracorporeal anastomosis in minimally invasive colectomies
}

\author{
Sean S. W. Park ${ }^{1,2}$, Daniel Feng ${ }^{3,4}$, Stephen Smith ${ }^{5,6}$ \\ 'Department of General Surgery, John Hunter Hospital, Newcastle, New South Wales 2305, Australia. \\ ${ }^{2}$ School of Medicine and Public Health, University of Edinburgh, Edinburgh EH8 9AB, United Kingdom. \\ ${ }^{3}$ Department of General Surgery, Westmead Hospital, Sydney, New South Wales 2145, Australia. \\ ${ }^{4}$ School of Medicine and Public Health, University of Newcastle, Newcastle, New South Wales 2308, Australia. \\ ${ }^{5}$ Department of General Surgery, John Hunter Hospital, Newcastle, New South Wales 2305, Australia. \\ ${ }^{6}$ School of Medicine and Public Health, University of Newcastle, Newcastle, New South Wales 2308, Australia.
}

Correspondence to: Dr. Daniel Feng, Westmead Hospital, Hawkesbury Rd, Westmead, New South Wales 2145, Australia. E-mail: d.feng1996@gmail.com

\begin{abstract}
How to cite this article: Park SSW, Feng D, Smith S. A systematic review and meta-analysis comparing intracorporeal anastomosis and extracorporeal anastomosis in minimally invasive colectomies. Mini-invasive Surg 2020;4:87.
\end{abstract} DOI: $10.20517 / 2574-1225.2020 .87$

Received: 30 Aug 2020 First Decision: 12 Oct 2020 Revised: 19 Oct 2020 Accepted: 30 Oct 2020 Published: 5 Dec 2020

Academic Editor: Simon Ng Copy Editor: Cai-Hong Wang Production Editor: Jing Yu

\begin{abstract}
Aim: This systemic review aims to determine if intracorporeal anastomosis (IA) adds value to patient outcomes without compromising operative and oncological safety when compared to extracorporeal anastomosis (EA) in laparoscopic colectomies. This is the first systematic review with meta-analysis to evaluate the outcomes in a combined fashion including both laparoscopic right and left colectomies.
\end{abstract}

Methods: A systematic review of Medline, EMBASE, Cochrane Library, and PubMed was performed on studies analysing direct comparison between IA and EA. The primary outcome was anastomotic leakage. Quality assessment was carried out using a modified Institute of Health Economics appraisal tool. Meta-analysis was performed using a random-effects model.

Results: A total of 24 papers with 2,674 patients were included in the analysis. No significant difference was found in anastomotic leakage $(\mathrm{OR}=0.84 ; 95 \% \mathrm{Cl}: 0.54-1.31 ; P=0.44)$ and short-term mortality $(\mathrm{OR}=0.56 ; 95 \% \mathrm{Cl}$ : $0.20-1.58 ; P=0.27$ ) between the IA and EA cohorts. The IA cohort was associated with faster return of bowel function $[\mathrm{MD}=-0.53$ days; $95 \% \mathrm{Cl}:-0.67-(-0.39) ; P<0.00001]$ and lower incidence of surgical site infection

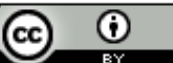

(C) The Author(s) 2020. Open Access This article is licensed under a Creative Commons Attribution 4.0 International License (https://creativecommons.org/licenses/by/4.0/), which permits unrestricted use sharing, adaptation, distribution and reproduction in any medium or format, for any purpose, even commercially, as long as you give appropriate credit to the original author(s) and the source, provide a link to the Creative Commons license, and indicate if changes were made. 
$(\mathrm{OR}=0.52 ; 95 \% \mathrm{Cl}: 0.31-0.85 ; P=0.009)$. The number of lymph nodes harvested was higher in IA $(M D=1.05$; 95\% Cl: 0.19-1.91; $P=0.02 ; I^{2}=83 \%$ ) with considerable heterogeneity.

Conclusion: Intracorporeal anastomosis can be considered a safe alternative technique in laparoscopic colectomies, with potential benefits in patient outcomes. A lack of randomised studies and heterogeneity need to be addressed by additional high-quality trials.

Keywords: Laparoscopic, intracorporeal, extracorporeal, colectomy, outcome

\section{INTRODUCTION}

Laparoscopic colectomy has been increasingly performed worldwide since its introduction and it is currently considered the "gold standard" surgical care for benign and malignant colon resections ${ }^{[1]}$. The most common indication for the colon resection is malignancy, which is the second leading cause of cancer death worldwide, with a lifetime incidence of approximately $6 \%{ }^{[2]}$.

In general, the term "laparoscopic colectomy" refers to laparoscopic-assisted colectomy with extracorporeal anastomosis (EA). Extracorporeal anastomosis is the preferred technique as intracorporeal anastomosis (IA) is considered more technically challenging due to the need for laparoscopic suturing and the potential risk of intra-abdominal spillage ${ }^{[3,4]}$. Subsequently, there has been concern about a greater likelihood of anastomotic leak ${ }^{[5]}$. However, IA is less invasive, and there is accumulating data to support its safety and potential short-term benefits in the post-operative period ${ }^{[6,7]}$. Unfortunately, available meta-analyses are limited to right colectomies based on limited observational studies while there is a paucity of data on left colectomies.

Traditionally, left colectomy is perceived to be more challenging than right colectomy due to the need for extensive posterior dissection during mobilisation of the splenic flexure and its anatomic characteristics of multiple lymphatic drainage. However, a study by Iorio et al. ${ }^{[8]}$, investigating direct comparison of surgical outcomes in laparoscopic IA approach between right-sided and left-sided tumours, concluded that the location of the tumour itself did not have significant impact on patient clinical outcome, including anastomotic leakage.

The aim of this study was, therefore, to conduct a comprehensive systematic review to perform a combined meta-analysis of left and right-sided colectomies in order to broaden the existing understanding on the safety and potential benefits of IA in laparoscopic colectomy, irrespective of its primary location.

\section{METHODS}

\section{Study design}

Literature search and data extraction

A systematic literature search was carried out by two independent researchers using electronic databases including Medline, EMBASE, Cochrane Library, and PubMed. The following search strategy was used for database extraction using Endnote (Version X8, Clarivate Analytics ${ }^{\circledR}$ ): "intracorporeal" OR "extracorporeal" OR "anastomosis" OR "laparoscopic assisted" OR "totally laparoscopic" AND "colectomy" and ("laparoscopy" or "laparoscopic"). The search was performed without any restriction on language or publication status. Studies published in a language other than English were excluded unless its full article was available in an English edition. 


\section{Inclusion and exclusion criteria}

The following inclusion criteria were prerequisite to be included in the meta-analysis: (1) direct comparison of the pre-determined outcomes of IA with EA involving right-sided and/or left-sided colectomies; and (2) reported data concerning at least the primary endpoint (i.e., anastomotic leakage). If two studies were reported by the same institution and/or authors, the one with more comprehensive data was included, unless the studies were of different design and encompassed distinctive study population.

Non-comparative studies such as case series, description of particular techniques, along with animal studies, conference abstracts, review articles, opinions and editorials were excluded from the analysis. Furthermore, studies with inadequate data or that described other types of resections (e.g., single-incision approach, purely robotic, sub-total colectomy, primary rectosigmoid resection, and palliative resection) were excluded as well. The natural orifice extraction studies were excluded as it is currently not a widely practiced method and its validity is still to be confirmed ${ }^{[9]}$.

\section{Outcome measures}

The primary endpoint was anastomotic leakage since the safety of a surgical technique is considered the most vital. An anastomotic leak was defined as a defect in the intestinal wall integrity at the anastomotic site leading to a communication between the intraluminal and extraluminal compartments either clinically or radiologically ${ }^{[10]}$.

With regard to the secondary outcomes, we chose the following clinical endpoints to best reflect crucial clinical consequences of colonic resection:

Intraoperative:

(1) Operative time

(2) Number of lymph nodes harvested

Post-operative:

(1) Mortality, defined as any deaths occurred during hospitalisation or within 30 days post-operatively

(2) Need for re-intervention

(3) Time to first flatus

(4) Surgical site infections

(5) Incidence of post-operative incisional hernia

\section{Data analysis}

\section{Statistical analysis}

The meta-analysis was performed using Review Manager 5.3 (Cochrane Community) and was conducted in accordance with recommendations from the Cochrane Collaboration and Meta-Analysis of Observational Studies in Epidemiology Guidelines.

The statistical analysis for dichotomous variables was summarised by calculating odds ratios (OR) with a confidence interval (CI) of $95 \%$. Mantel-Haenszel method was used to calculate the effect size by combining the odds ratios of the outcomes using a random-effects model. Odds ratio $<1$ favoured the IA group while odds ratio $>1$ favoured the EA group. This was considered statistically significant if $P<0.05$ and if the confidence interval did not include 1 . Continuous variables were statistically analysed by calculating the weighted mean difference (WMD) with a 95\% confidence interval. A positive WMD indicated that the pooled mean value of the outcome was higher in the IA group and was considered statistically significant if $P<0.05$. Study heterogeneity was evaluated using $I^{2}$ statistics. $I^{2}>50 \%$ was considered substantial (i.e., serious heterogeneity) while $I^{2}<50 \%$ was considered low-moderate risk of heterogeneity. In studies which 


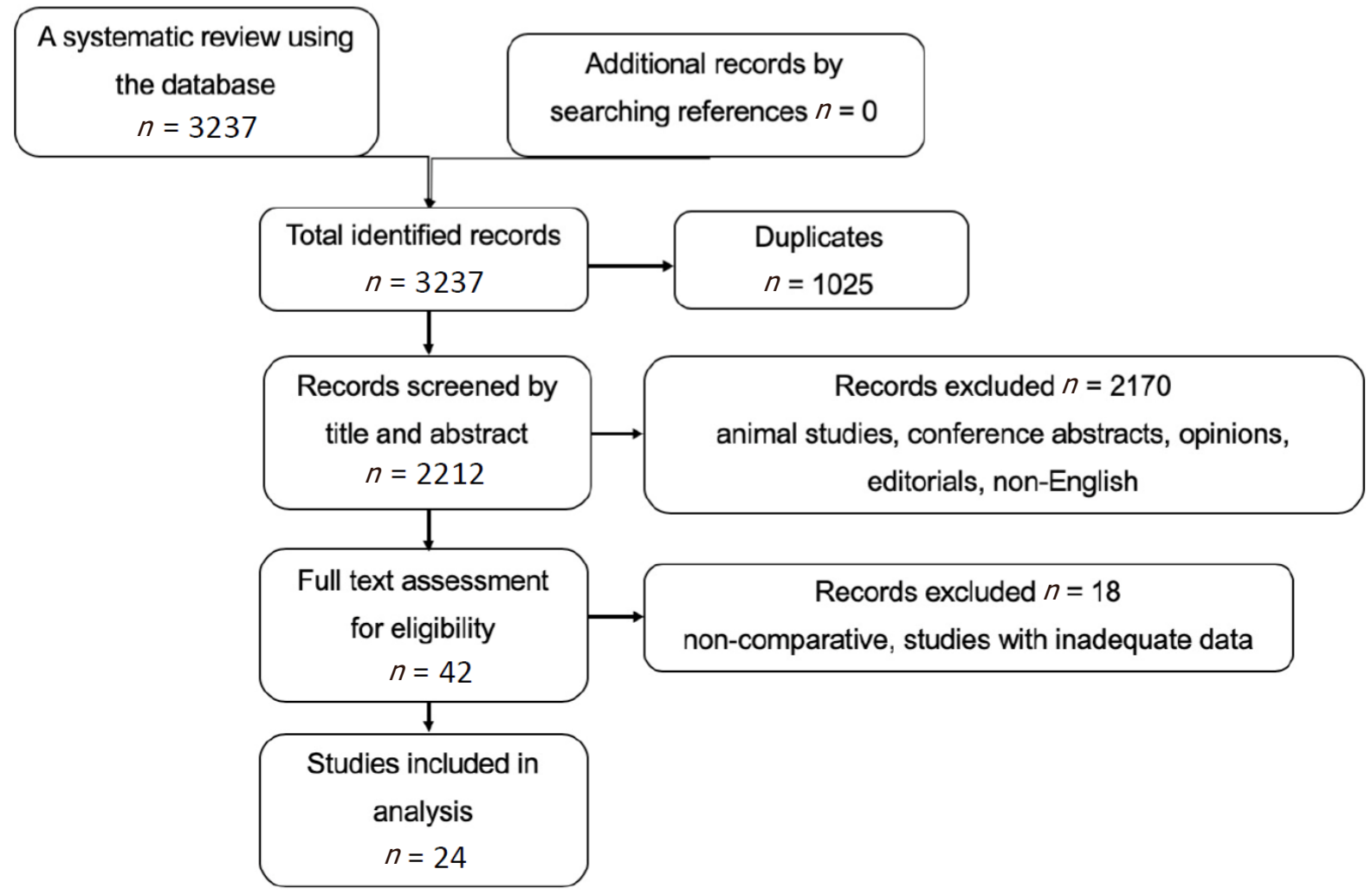

Figure 1. PRISMA flowchart for the systematic review of literature

included median with range, a dedicated mathematical conversion to mean and standard deviation was carried out using methods from Wan et al. ${ }^{[11]}$.

Forest plots were constructed for meta-analysis on pre-determined outcomes by evaluating the total colectomies combined. A meta regression analysis and leave-one-out analysis were performed for the primary outcome to identify potential heterogeneity. Publication bias was assessed using Begg's and Egger's test.

\section{RESULTS}

\section{Included articles}

The flow chart on search results of the literature in accordance with the PRISMA statement are displayed in Figure 1. The search identified a total number of 3,237 potential articles published between 1991 and 2019. A total of 42 articles met initial inclusion criteria and full-text articles were reviewed. After thorough process of literature review and discussion between two independent reviewers, 24 papers were determined to be eligible for data extraction and subsequent statistical analysis. Cross-checking of all references of the included papers did not identify any additional studies.

The included studies for final analysis resulted in a total of 2,674 patients who had undergone laparoscopic colectomy. This was split into 1,412 patients $(52.8 \%)$ in the intervention group (i.e., intracorporeal anastomosis) and 1,262 (47.2\%) in the control group (i.e., extracorporeal anastomosis). The study design and characteristics of each study included are described in Table 1.

Two papers were identified to have been published by the same author, Vignali et al ${ }^{[12,13]}$. After a thorough review, both studies were considered for inclusion in our analysis as they were of different study design, with Vignali et al. ${ }^{[12]}$ evaluating the outcomes in a specific patient cohort, the obese population, as evident 


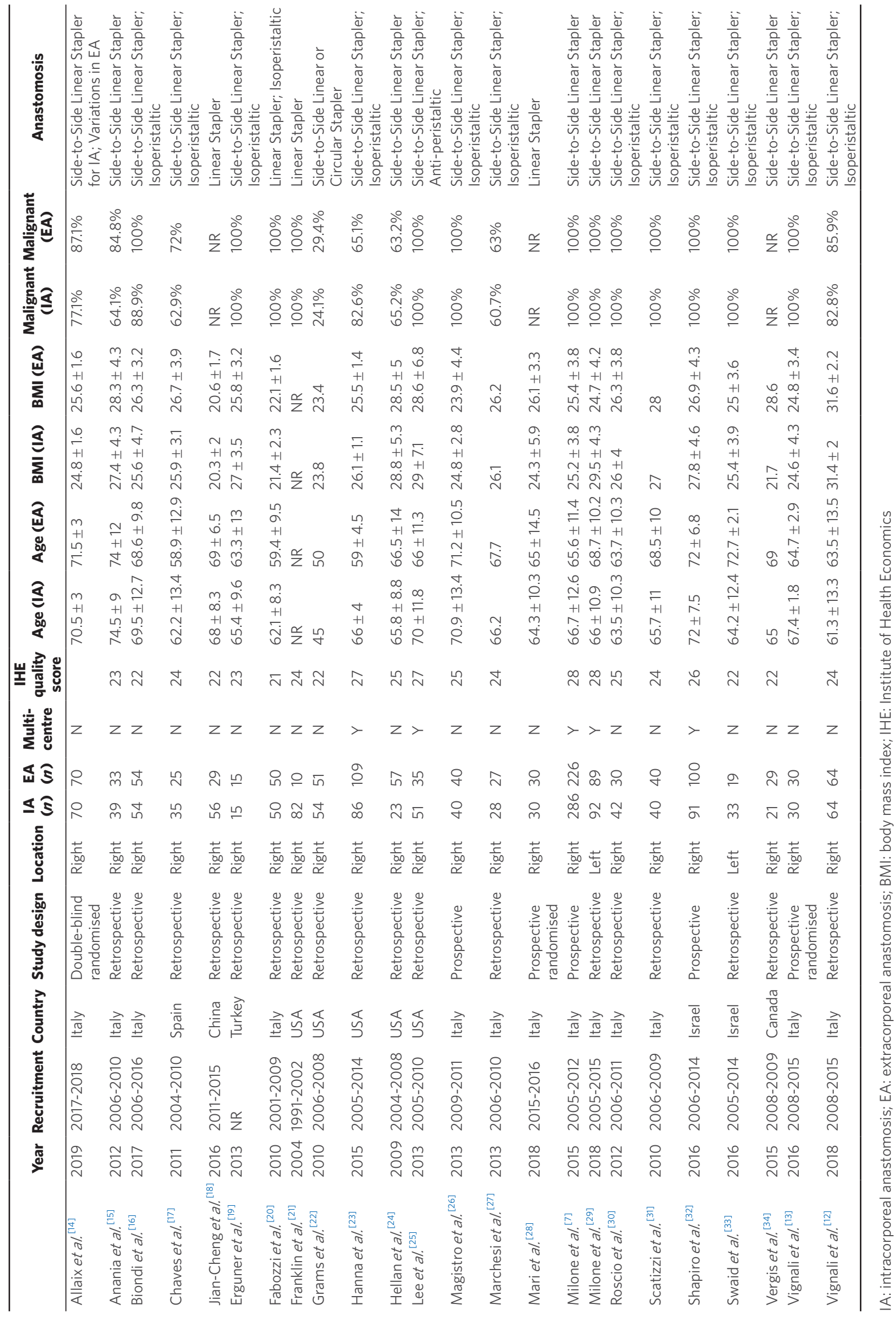




\begin{tabular}{|c|c|c|c|c|c|c|c|c|c|}
\hline Study or Subgroup & \multicolumn{2}{|c|}{ Intracorporeal } & \multicolumn{2}{|c|}{ Extracorporeal } & Weight & $\begin{array}{c}\text { Odds Ratio } \\
\mathrm{M}-\mathrm{H} \text {, Random, } 95 \% \mathrm{Cl}\end{array}$ & \multicolumn{3}{|c|}{$\begin{array}{c}\text { Odds Ratio } \\
\mathrm{M}-\mathrm{H}, \text { Random, } 95 \% \mathrm{Cl}\end{array}$} \\
\hline Allaix 2019 & 6 & 70 & 2 & 70 & $72 \%$ & $3.19[0.62,16.37]$ & & & \\
\hline Anania 2012 & 2 & 39 & 2 & 33 & $4.7 \%$ & $0.84[0.11,6.30]$ & & & \\
\hline Biondi 2017 & 0 & 54 & 2 & 54 & $2.1 \%$ & $0.19[0.01,4.11]$ & & & \\
\hline Chaves 2010 & 3 & 35 & 0 & 25 & $2.1 \%$ & $5.49[0.27,111.23]$ & & & \\
\hline Cheng 2016 & 0 & 56 & 0 & 29 & & Not estimable & & & \\
\hline Erguner 2012 & 1 & 15 & 2 & 15 & $3.0 \%$ & $0.46[0.04,5.75]$ & & & \\
\hline Fabozi 2010 & 0 & 50 & 3 & 50 & $2.2 \%$ & $0.13[0.01,2.67]$ & & & \\
\hline Franklin 2004 & 0 & 82 & 0 & 10 & & Not estimable & & & \\
\hline Grams 2010 & 0 & 54 & 1 & 51 & $1.9 \%$ & $0.31[0.01,7.76]$ & & & \\
\hline Hanna 2015 & 4 & 86 & 9 & 109 & $13.1 \%$ & $0.54[0.16,1.82]$ & & & \\
\hline Hellan 2009 & 1 & 23 & 1 & 57 & $2.4 \%$ & $2.55[0.15,42.51]$ & & & \\
\hline Lee 2013 & 4 & 51 & 2 & 35 & $6.2 \%$ & $1.40[0.24,8.12]$ & & & \\
\hline Magistro 2013 & 0 & 40 & 0 & 40 & & Not estimable & & & \\
\hline Marchesi 2013 & 0 & 28 & 0 & 27 & & Not estimable & & & \\
\hline Mari 2018 & 0 & 30 & 1 & 30 & $1.8 \%$ & $0.32[0.01,8.24]$ & & & \\
\hline Milone 2014 & 12 & 286 & 12 & 226 & $28.6 \%$ & $0.78[0.34,1.77]$ & & 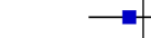 & - \\
\hline Milone 2018 & 2 & 92 & 1 & 89 & $3.3 \%$ & $1.96[0.17,21.96]$ & & & \\
\hline Roscio 2012 & 1 & 42 & 1 & 30 & $2.4 \%$ & $0.71[0.04,11.78]$ & & & \\
\hline Scatizi 2010 & 0 & 40 & 0 & 40 & & Not estimable & & & \\
\hline Shapiro 2015 & 1 & 91 & 4 & 100 & $3.9 \%$ & $0.27[0.03,2.43]$ & & & \\
\hline Swaid 2015 & 1 & 33 & 0 & 19 & $1.8 \%$ & $1.80[0.07,46.40]$ & & & \\
\hline Vergis 2014 & 1 & 21 & 1 & 29 & $2.4 \%$ & $1.40[0.08,23.74]$ & & & \\
\hline Vignali 2016 & 2 & 30 & 0 & 30 & $2.0 \%$ & $5.35[0.25,116.31]$ & & & \\
\hline Vignali 2017 & 3 & 64 & 5 & 64 & $8.8 \%$ & $0.58[0.13,2.54]$ & & & \\
\hline Total $(95 \% \mathrm{Cl})$ & & 1412 & & 1262 & $100.0 \%$ & $0.84[0.54,1.31]$ & & & \\
\hline Total events & 44 & & 49 & & & & & & \\
\hline $\begin{array}{l}\text { Heterogeneity: Tau } \\
\text { Test for overall effec }\end{array}$ & $\begin{array}{l}0.00 ; \mathrm{Chi}^{2} \\
\mathrm{Z}=0.77(t\end{array}$ & $\begin{array}{l}12.24 \\
0.44)\end{array}$ & $=18(P$ & 83) & $=0 \%$ & & 0.01 & $\begin{array}{l}0.1 \\
\text { Favours [IA] }\end{array}$ & $\begin{array}{c}10 \\
\text { Favours [EA] }\end{array}$ \\
\hline
\end{tabular}

Figure 2. Meta-analysis of anastomotic leakage

by the significant difference in average body mass index (BMI) of the patient cohort included in the study [Table 1 $]^{[12]}$.

\section{Study characteristics and demographic data}

The surgical technique used to perform IA anastomosis was similar in all included studies. A mechanical linear stapler was the method of choice for bowel anastomosis for both intracorporeal and extracorporeal approach, reported in all 24 articles. However, a large variation was noted among published literature for the closure of enterotomies and the length of anastomosis.

The overall mean age, reported in twenty-three articles, was 65.7 years in the IA group and 66.0 years in the EA group. The male to female ratio was 1.1:1 for IA cohort and 1:1 for the EA. The average BMI, reported in 23 papers, was $25.8 \mathrm{~kg} / \mathrm{m}^{2}$ for the IA cohort and $26.0 \mathrm{~kg} / \mathrm{m}^{2}$ for the EA group.

\section{Quality assessment: modified Institute of Health Economics quality appraisal tool}

The modified Institute of Health Economics (IHE) quality appraisal tool used is displayed in Supplement Table $1^{[35]}$. The assessment was conducted for 21 comparative, non-randomised studies. The mean score was 24.2 (range 21-28) out of a total of 30 points. Study with a score $\geq 26$ was considered of high quality.

\section{Meta-analysis}

Primary outcome

Anastomotic Leakage: The overall rate of anastomotic leakage [Figure 2] reported in 24 articles was 3.1\% (44 cases) for the IA and 3.9\% (49 cases) for the EA. The meta-analysis did not reveal a statistically significant difference $\left(\mathrm{OR}=0.84 ; 95 \% \mathrm{CI}: 0.54-1.31 ; P=0.44 ; I^{2}=0 \%\right)$.

\section{Secondary outcomes}

Operative time: The operative time [Figure 3] was reported in 21 studies. It was 10 min longer for IA (MD $=9.99 \mathrm{~min} ; 95 \% \mathrm{CI}: 3.68-16.31 ; P=0.002 ; I^{2}=85 \%$, which was statistically significant. 


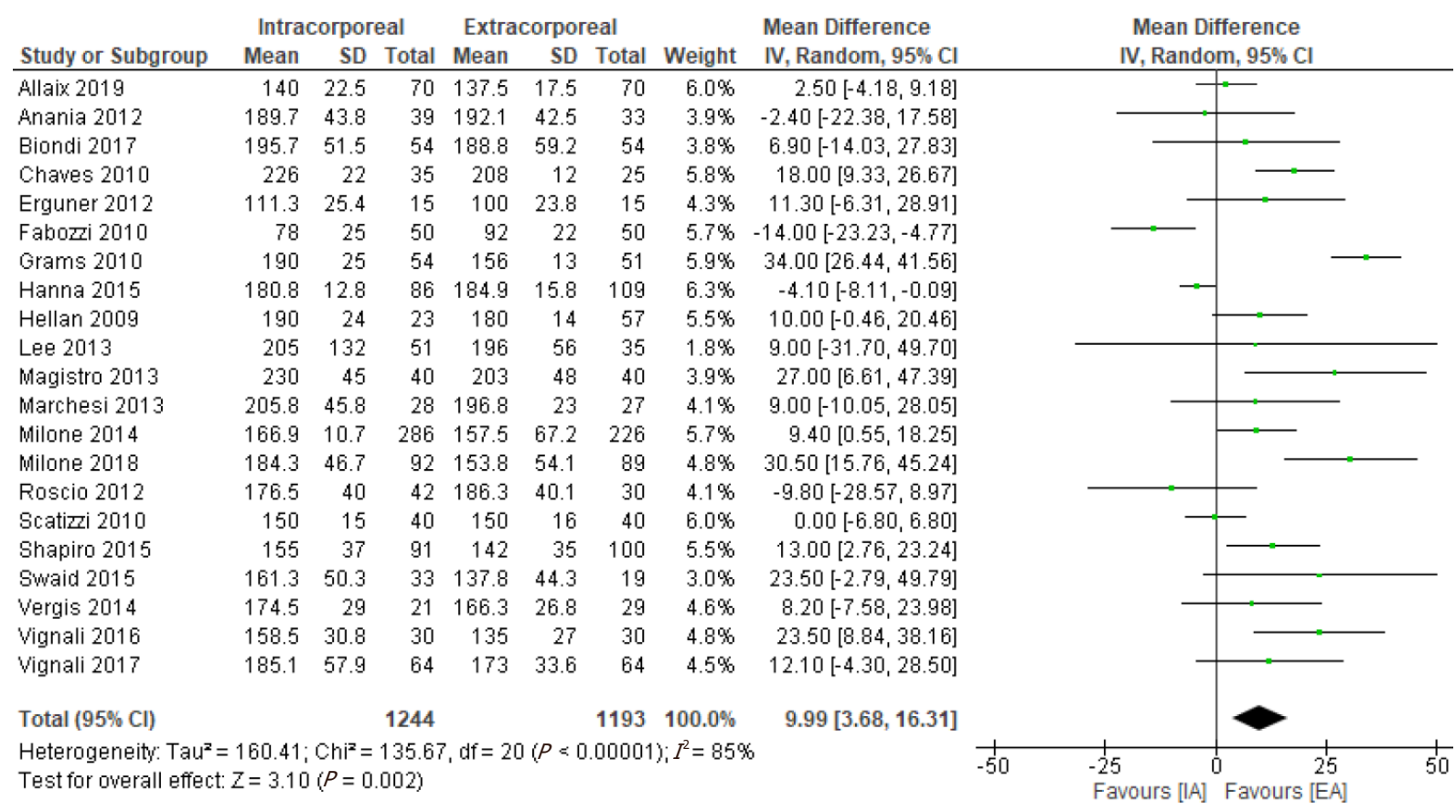

Figure 3. Meta-analysis of operative time

Lymph node harvesting: The number of lymph nodes harvested [Figure 4] in oncological resections was documented in 19 studies. Meta-analysis demonstrated that IA was associated with higher number of lymph nodes harvested ( $\mathrm{MD}=1.05 ; 95 \% \mathrm{CI}: 0.19-1.91 ; P=0.02 ; I^{2}=83 \%$ ). This was statistically significant but with considerable heterogeneity.

Mortality: Mortality was reported in 22 studies [Figure 5]. There were 3 deaths in the IA group and 8 in the EA group. No statistically significant difference was observed between the two groups $(\mathrm{OR}=0.56$; $95 \% \mathrm{CI}$ : $\left.0.20-1.58 ; P=0.27 ; I^{2}=0 \%\right)$.

Post-operative surgical complications: The indicators of post-operative complications were comprised of the incidence of surgical site infection, incisional hernia, and the need for re-intervention.

Post-operative surgical site infection [Figure 6] was investigated in 20 studies. The rate of post-operative wound infection was $3.7 \%$ (46 cases) in IA and 7.7\% (90 cases) in EA. The incidence of post-operative incisional hernia [Figure 7] was evaluated in 12 articles, and the rate of incisional hernia development was $2.8 \%$ (17 cases) in IA and 10.9\% (67 cases) in EA. Meta-analysis demonstrated that the incidence of surgical site infection $\left(\mathrm{OR}=0.52\right.$; 95\%CI: $\left.0.31-0.85 ; P=0.009 ; I^{2}=27 \%\right)$ and incisional hernia $(\mathrm{OR}=0.30 ; 95 \% \mathrm{CI}$ : $\left.0.17-0.53 ; P<0.0001 ; I^{2}=0 \%\right)$ was significantly lower in IA group.

The need for re-intervention [Figure 8] demonstrated no statistically significant difference between the two groups $\left(\mathrm{OR}=0.72 ; 95 \% \mathrm{CI}: 0.45-1.16 ; P=0.18 ; I^{2}=0 \%\right)$.

Return of bowel function outcomes: Time to first flatus was reported in 13 studies [Figure 9]. The analysis demonstrated that the patients in IA group had faster return to gut function as measured by first flatus [MD $=-0.53$ days; $95 \%$ CI: $\left.-0.67-(-0.39) ; P<0.00001 ; I^{2}=56 \%\right]$.

Heterogeneity: The heterogeneity was low for the primary endpoint (i.e., $I^{2}=0$ for anastomotic leakage). However, it was variable for the secondary outcomes. The heterogeneity was low for mortality, surgical 


\begin{tabular}{|c|c|c|c|c|c|c|c|c|c|c|}
\hline \multirow[b]{2}{*}{ Study or Subgroup } & \multicolumn{3}{|c|}{ Intracorporeal } & \multicolumn{3}{|c|}{ Extracorporeal } & \multirow[b]{2}{*}{ Weight } & \multirow{2}{*}{$\begin{array}{l}\text { Mean Difference } \\
\text { IV, Random, } 95 \% \mathrm{Cl}\end{array}$} & \multirow{2}{*}{\multicolumn{2}{|c|}{$\begin{array}{l}\text { Mean Difference } \\
\text { IV, Random, } 95 \% \mathrm{Cl}\end{array}$}} \\
\hline & Mean & SD & Total & Mean & SD & Total & & & & \\
\hline Allaix 2019 & 17.5 & 2.5 & 70 & 16.5 & 2.5 & 70 & $9.3 \%$ & $1.00[0.17,1.83]$ & & \\
\hline Anania 2012 & 20.3 & 7.3 & 39 & 14.8 & 6.8 & 33 & $4.1 \%$ & $5.50[2.24,8.76]$ & & \\
\hline Biondi 2017 & 19.2 & 6.7 & 54 & 15.2 & 3.7 & 54 & $6.5 \%$ & $4.00[1.96,6.04]$ & & \\
\hline Chaves 2010 & 20.7 & 6 & 35 & 14.3 & 5 & 25 & $4.9 \%$ & $6.40[3.61,9.19]$ & & \\
\hline Cheng 2016 & 18.5 & 0.4 & 56 & 19.2 & 0.4 & 29 & $10.1 \%$ & $-0.70[-0.88,-0.52]$ & $=$ & \\
\hline Erguner 2012 & 27 & 9.7 & 15 & 25 & 7.6 & 15 & $1.6 \%$ & $2.00[-4.24,8.24]$ & & \\
\hline Fabozzi 2010 & 16.1 & 2.5 & 50 & 17.2 & 2.3 & 50 & $9.1 \%$ & $-1.10[-2.04,-0.16]$ & & \\
\hline Hanna 2015 & 19.6 & 2.8 & 86 & 19.4 & 1.9 & 109 & $9.5 \%$ & $0.20[-0.49,0.89]$ & & \\
\hline Hellan 2009 & 18 & 5 & 23 & 17 & 4 & 57 & $5.9 \%$ & $1.00[-1.29,3.29]$ & & \\
\hline Lee 2013 & 24 & 10 & 51 & 23.5 & 11.5 & 35 & $2.5 \%$ & $0.50[-4.20,5.20]$ & & \\
\hline Magistro 2013 & 22 & 10 & 40 & 20 & 10 & 40 & $2.8 \%$ & $2.00[-2.38,6.38]$ & & \\
\hline Marchesi 2013 & 20.9 & 9.1 & 28 & 17.3 & 9.8 & 27 & $2.3 \%$ & $3.60[-1.40,8.60]$ & & \\
\hline Milone 2014 & 25.7 & 10.7 & 286 & 24.8 & 8.7 & 226 & $7.3 \%$ & $0.90[-0.78,2.58]$ & & \\
\hline Milone 2018 & 18.5 & 9 & 92 & 17.5 & 8.4 & 89 & $5.4 \%$ & $1.00[-1.54,3.54]$ & & \\
\hline Roscio 2012 & 25.9 & 9 & 42 & 22 & 8.2 & 30 & $3.2 \%$ & $3.90[-0.10,7.90]$ & & \\
\hline Scatizzi 2010 & 30 & 17 & 40 & 32 & 14 & 40 & $1.4 \%$ & $-2.00[-8.82,4.82]$ & & \\
\hline Shapiro 2015 & 20.3 & 4.5 & 91 & 23.5 & 8 & 100 & $7.0 \%$ & $-3.20[-5.02,-1.38]$ & & \\
\hline Swaid 2015 & 12.9 & 5.7 & 33 & 11.2 & 4.2 & 19 & $5.1 \%$ & $1.70[-1.01,4.41]$ & & \\
\hline Vignali 2016 & 21.5 & 9.8 & 30 & 22.4 & 12 & 30 & $2.0 \%$ & $-0.90[-6.44,4.64]$ & & \\
\hline Total $(95 \% \mathrm{Cl})$ & & & 1161 & & & 1078 & $100.0 \%$ & $1.05[0.19,1.91]$ & & \\
\hline \multicolumn{9}{|c|}{$\begin{array}{l}\text { Heterogeneity: } \operatorname{Tau}^{2}=1.91 ; \mathrm{Ch}^{2}=104.11, \mathrm{df}=18(P \leq 0.00001) ; I^{2}=83 \% \\
\text { Test for overall effect: } Z=2.38(P=0.02)\end{array}$} & $\begin{array}{ll}-4 & -2 \\
\text { avours }[E A]\end{array}$ & $\begin{array}{ccc} & 1 & 4 \\
& \text { Favours [IA }\end{array}$ \\
\hline
\end{tabular}

Figure 4. Meta-analysis of lymph node harvesting

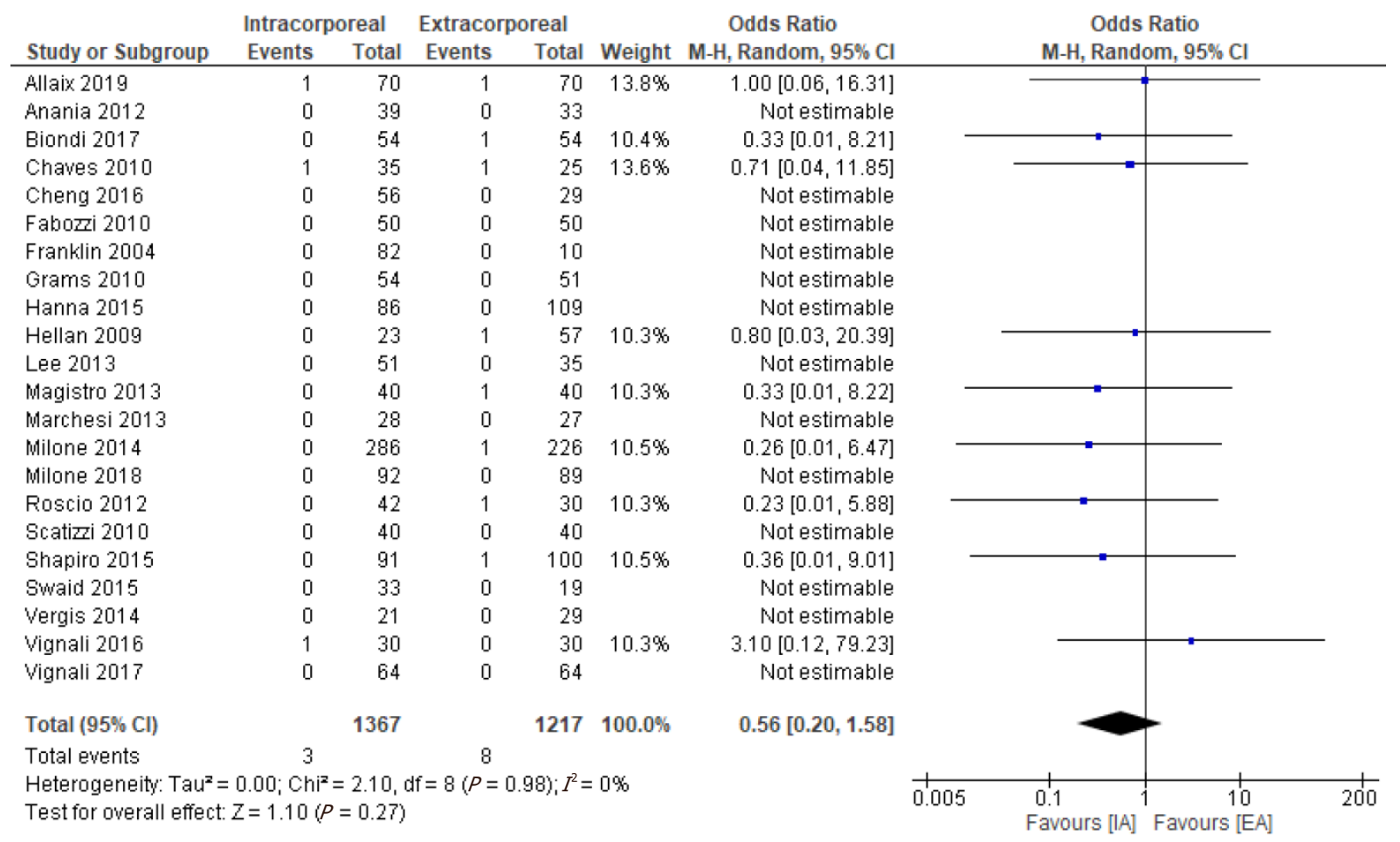

Figure 5. Meta-analysis of mortality

site infection, incisional hernia, and the need for re-intervention. On the other hand, it was considered substantial for operative time, time to first flatus, and lymph node harvesting.

Meta-regression analysis: Four covariates were assessed to determine their influences on heterogeneity, including median year of patient recruitment, retrospective $v s$. prospective study, study quality, and left 


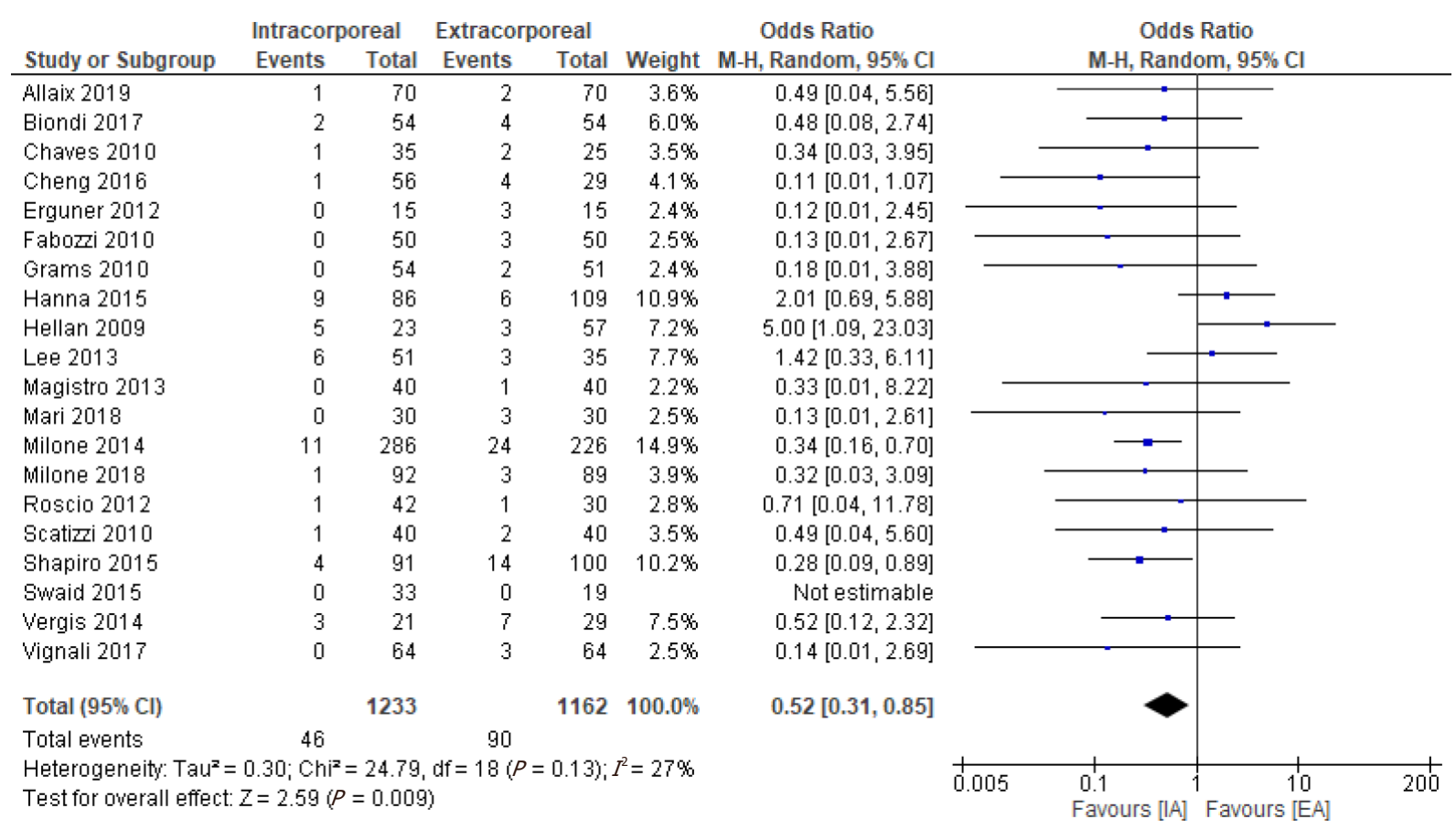

Figure 6. Meta-analysis of surgical site infection

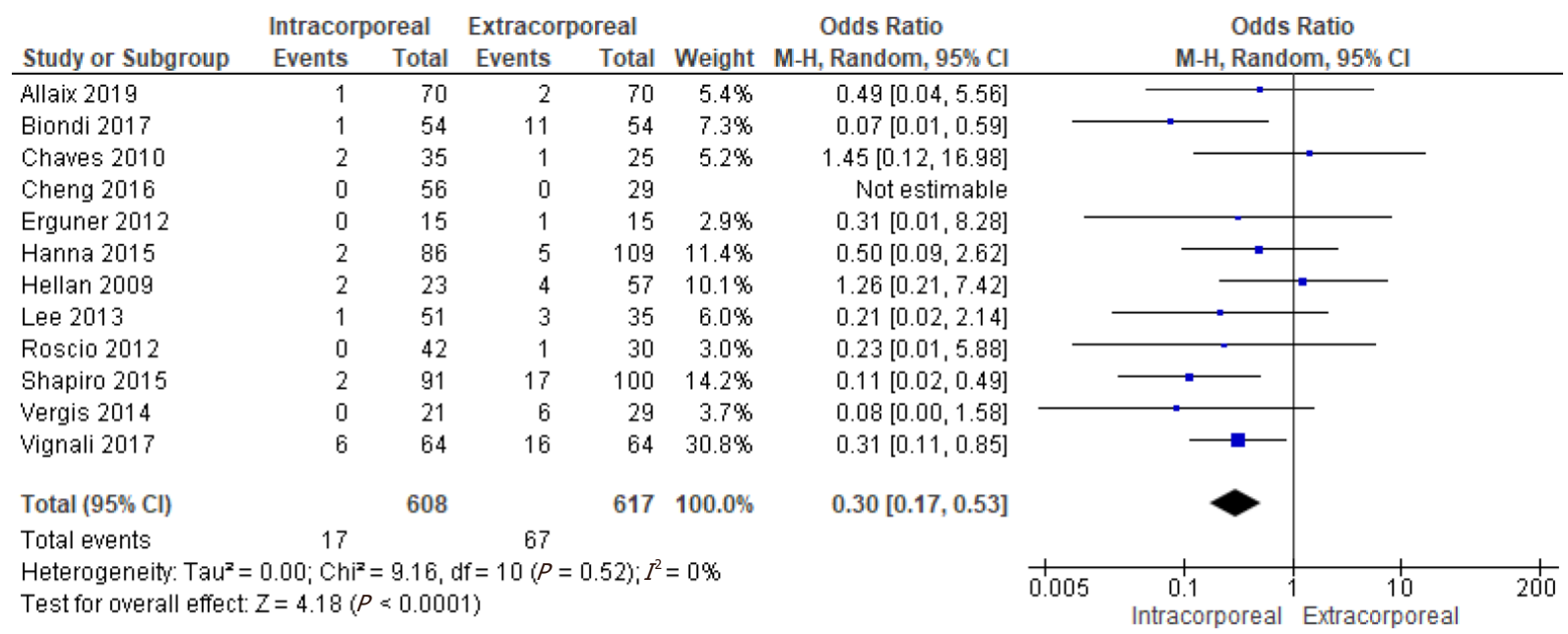

Figure 7. Meta-analysis of incisional hernia

vs. right colectomy. Univariable meta-regression did not identify any of these covariates to be a significant influence for the primary outcome.

Publication bias: No evidence of publication bias was found for the primary outcome (Begg's $P=0.520$; Egger's $P=0.640$ ). Visual examination of funnel plots for those outcomes did not demonstrate asymmetry, as evidenced in Figure 10.

Leave-one-out analysis for the primary outcome, anastomotic leakage [Figure 11], was conducted to evaluate the odds ratio when individual studies were removed. No major changes to the results were observed for anastomotic leakage $(\mathrm{OR}=0.84 ; 95 \% \mathrm{CI}$ : 0.54-1.32). 


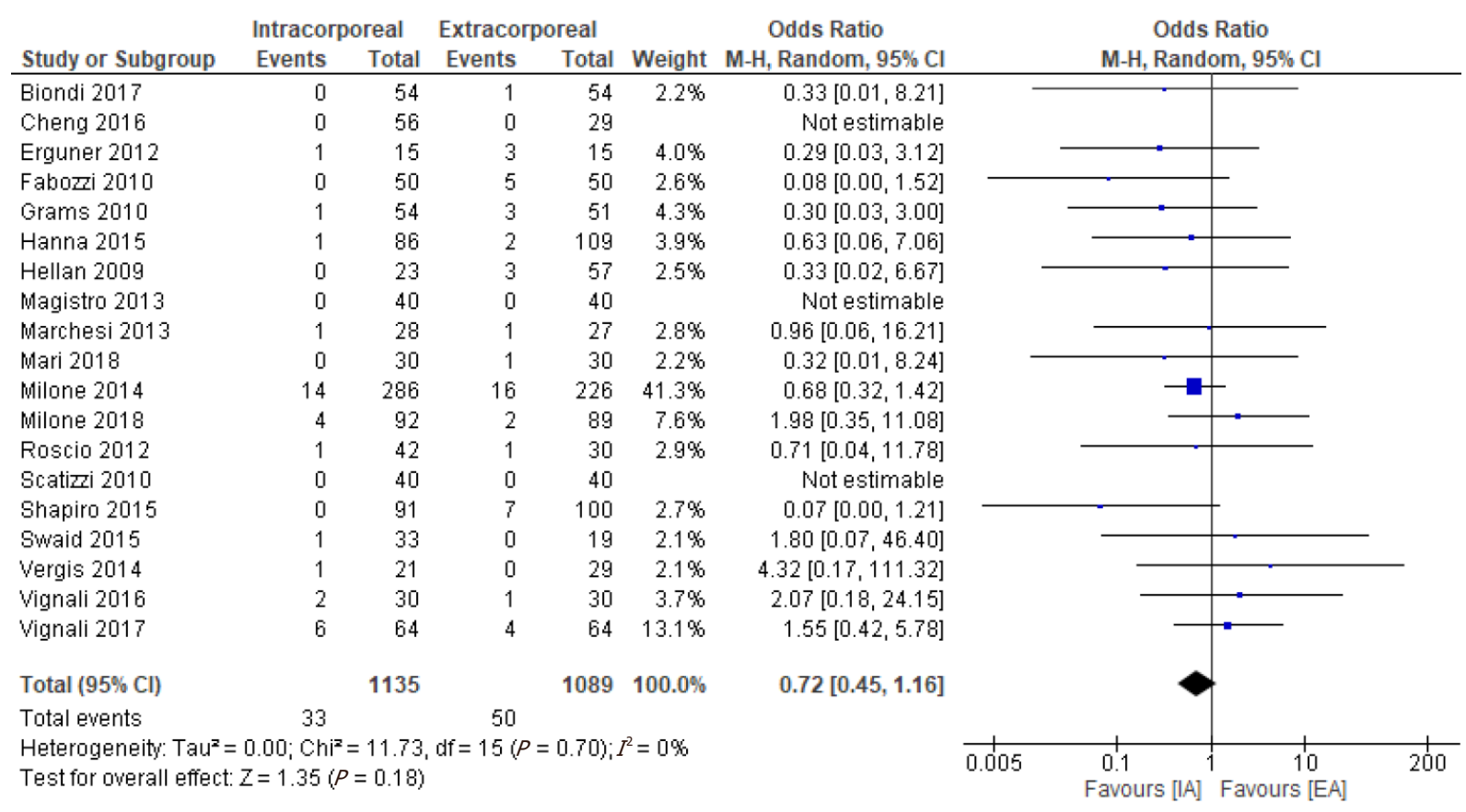

Figure 8. Meta-analysis of need for re-intervention

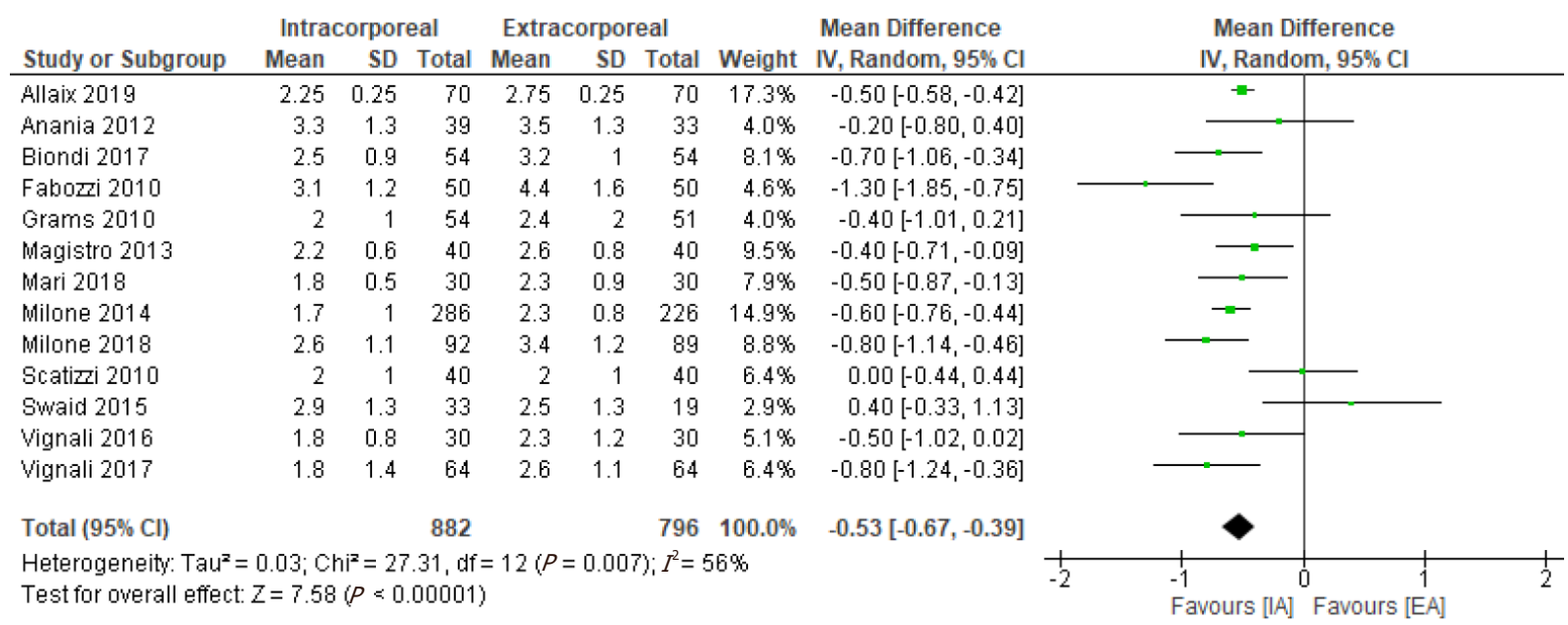

Figure 9. Meta-analysis of time to first flatus

\section{Subgroup analysis on left colectomy}

In our systematic review, only three studies were found to have met the search criteria with direct comparison on anastomotic leakage between intracorporeal and extracorporeal anastomosis in leftsided colectomy. After a careful review, only two studies ${ }^{[29,33]}$ were eligible for further analysis, with a total number of 233 patients (125 IA vs. $108 \mathrm{EA}$ ). A meta-analysis was conducted for the primary outcome of anastomotic leak, which did not demonstrate a significant difference between the two cohorts $(\mathrm{OR}=1.90$; 95\%CI: 0.27-13.21; $P=0.52 ; I^{2}=0 \%$ ) [Figure 12]. However, these studies were non-randomised with a lack of long-term follow-up, and it was perceived that further subgroup meta-analysis on left colectomy alone, with Milone et al ${ }^{[29]}$ imposing significantly higher weight (64.4\%), would be unlikely to produce meaningful results and therefore was not conducted. 


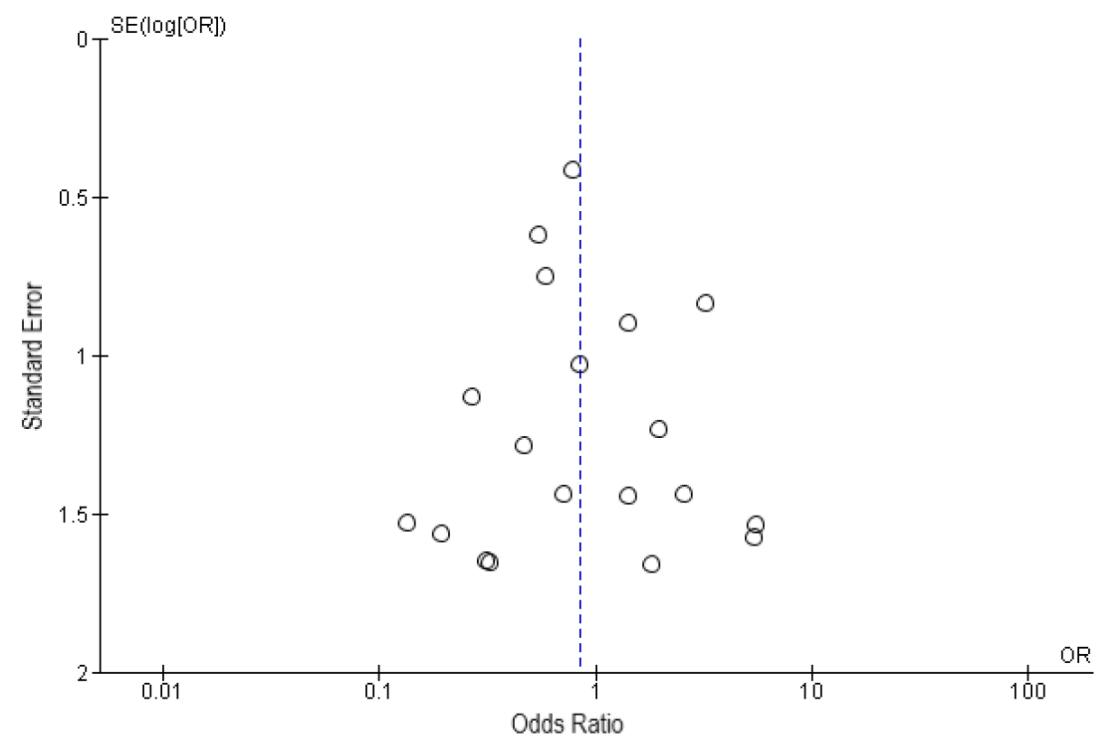

Figure 10. Funnel plot for anastomotic leak

\begin{tabular}{ll}
\multicolumn{1}{c}{ Study } & Odds Ratio $[95 \% \mathrm{Cl}]$ \\
Omitting Allaix 2019 & OR $0.76[0.48,1.20]$ \\
Omitting Anania 2012 & OR $0.84[0.54,1.32]$ \\
Omitting Biondi 2017 & OR $0.87[0.56,1.35]$ \\
Omitting Chaves 2010 & OR $0.81[0.52,1.26]$ \\
Omitting Cheng 2016 & OR $0.84[0.54,1.31]$ \\
Omitting Erguner 2012 & OR $0.86[0.55,1.34]$ \\
Omitting Fabozzi 2010 & OR $0.88[0.56,1.37]$ \\
Omitting Franklin 2004 & OR $0.84[0.54,1.31]$ \\
Omitting Grams 2010 & OR $0.86[0.55,1.34]$ \\
Omitting Hanna 2015 & OR $0.90[0.56,1.44]$ \\
Omitting Hellan 2009 & OR $0.82[0.53,1.28]$ \\
Omitting Lee 2013 & OR $0.81[0.52,1.28]$ \\
Omitting Magistro 2013 & OR $0.84[0.54,1.31]$ \\
Omitting Marchesi 2013 & OR $0.84[0.54,1.31]$ \\
Omitting Mari 2018 & OR $0.86[0.55,1.33]$ \\
Omitting Milone 2014 & OR $0.87[0.52,1.46]$ \\
Omitting Milone 2018 & OR $0.82[0.52,1.28]$ \\
Omitting Roscio 2012 & OR $0.85[0.54,1.32]$ \\
Omitting Scatizzi 2010 & OR $0.84[0.54,1.31]$ \\
Omitting Shapiro 2015 & OR $0.88[0.56,1.38]$ \\
Omitting Swaid 2015 & OR $0.83[0.53,1.29]$ \\
Omitting Vergis 2014 & OR $0.83[0.53,1.30]$ \\
Omitting Vignali 2016 & OR $0.81[0.52,1.26]$ \\
Omitting Vignali 2017 & OR $0.87[0.55,1.38]$ \\
$===============================================$ \\
Random Effect Model & \\
\hline
\end{tabular}

Figure 11. Leave one out analysis for anastomotic leak 


\begin{tabular}{|c|c|c|c|c|c|c|c|c|c|}
\hline Study or Subgroup & \multicolumn{2}{|c|}{ Intracorporeal } & \multicolumn{2}{|c|}{ Extracorporeal } & Weight & $\begin{array}{c}\text { Odds Ratio } \\
\text { M-H, Random, } 95 \% \mathrm{Cl}\end{array}$ & \multicolumn{3}{|c|}{$\begin{array}{c}\text { Odds Ratio } \\
\text { M-H, Random, } 95 \% \mathrm{Cl}\end{array}$} \\
\hline Milone 2018 & 2 & 92 & 1 & 89 & $64.4 \%$ & $1.96[0.17,21.96]$ & & & \\
\hline Swaid 2015 & 1 & 33 & 0 & 19 & $35.6 \%$ & $1.80[0.07,46.40]$ & & & \\
\hline Total $(95 \% \mathrm{CI})$ & & 125 & & 108 & $100.0 \%$ & $1.90[0.27,13.21]$ & & & \\
\hline Total events & 3 & & 1 & & & & & & \\
\hline $\begin{array}{l}\text { Heterogeneity: } \mathrm{Tau}^{2} \\
\text { Test for overall effec }\end{array}$ & $\begin{array}{l}0.00 ; C h i \\
Z=0.65\end{array}$ & $\begin{array}{l}=0.00 \\
D=0.5\end{array}$ & 2) $\mathrm{df}=1$ & $=0.97$ & $; I^{2}=0 \%$ & & 0.01 & $0.1{ }^{1}$ & $\begin{array}{r}10 \\
\text { Favours [EA] }\end{array}$ \\
\hline
\end{tabular}

Figure 12. Subgroup meta-analysis of anastomotic leak in left colectomy

\section{DISCUSSION}

There is a growing body of evidence in the literature that intracorporeal anastomosis is a safe alternative to extracorporeal anastomosis in laparoscopic right hemicolectomy ${ }^{[3-5]}$. However, we found that currently published systematic reviews and meta-analyses have not included more recently published studies, and have only compared right sided colectomies, with little research into left colectomies. As a result, we have carried out a new meta-analysis in an attempt to evaluate the clinical and oncological appropriateness of intracorporeal anastomosis technique, combining data on right-sided and left-sided laparoscopic colectomies and including more recently published studies. The strengths of this meta-analysis are that it provides more power to the analysis, allows for identification of more patients in each study arm through meticulous methodology, and offers thorough selection process and critical analysis of the results. To the best of our knowledge, this is the first systematic review with meta-analysis of the literature evaluating comprehensive peri-operative outcomes between IA and EA in a combined fashion including both laparoscopic right and left colectomies. Twenty-four studies were included for analysis, with an overall sample size of 2,674 patients (1,412 in the IA and 1,262 in the EA arm).

In terms of the primary outcome, the analysis supports the surgical safety of performing intracorporeal anastomosis in laparoscopic colectomy, with no statistically significant difference observed for the rate of anastomotic leakage. The quality of data is reinforced by an adequate sample size as well as an absence of heterogeneity and publication bias.

Concerning the secondary outcomes, our results from meta-analysis appear to favour IA when compared to EA, as evidenced by improved patient recovery with earlier return of bowel function, and lower rates of surgical site infections and incisional hernia, all of which were statistically significant. Moreover, this was without compromising oncological safety and short-term mortality.

Since the most common indication for laparoscopic colon resection is malignancy, it is imperative to consider the oncological safety of a surgical technique. We have selected the number of lymph nodes harvested as a surrogate marker for appropriateness of oncological radicality as the data was readily available in the literature but also an area of debate for many years. Our analysis revealed that IA was associated with slightly higher number of lymph nodes harvested. However, we acknowledge that the number of lymph nodes harvested alone does not truly represent the adequacy of oncological resection, and other crucial factors known to determine oncological safety such as clear multi-dimensional resection margins, minimal intraoperative manipulation of the tumour, and wound protection during specimen extraction all need to be considered. Therefore, we believe oncological safety would be better reflected by long-term survival and recurrence outcome. Unfortunately, only two studies, Hanna et al. ${ }^{[36]}$ and Lee et al. ${ }^{[25]}$, published meaningful long-term survival outcome with Kaplan-Meier graphs. Those studies demonstrated that there was no significant difference in both disease-free survival and overall survival at 5 years and 3 years between IA and EA cohorts respectively. 
Our data demonstrated that operative time was significantly longer with the IA technique by 10 min on weighted mean difference when compared to the EA technique. Although this was statistically significant, large variations in operative time reported in included studies were reflected by serious heterogeneity in our analysis $\left(I^{2}=85 \%\right)$. Operative time can be influenced by a multitude of factors beyond technical aspects alone, which may include fat distribution in individual patient, adhesions from previous abdominal surgery, extension of the tumour, and/or experience of individual surgeon to account for the learning curve effect. Unfortunately, however, these potential confounders were not easily identifiable in the available studies.

The lower rates of surgical site infections and incisional hernia observed in the IA cohort may be chiefly attributed to the extraction site. The IA approach allows flexibility when choosing the location of the incision for specimen extraction. In our analysis, the most common extraction site in the IA cohort (described explicitly in 15 studies) was through Pfannenstiel incision on the suprapubic port site, which is well recognised to result in good cosmetic satisfaction with low morbidity, less pain, and lower rates of incisional hernias ${ }^{[37]}$.

The return of bowel function was faster in the IA cohort, which is consistent with the widely accepted theory that patients undergoing IA are expected to undergo reduced manipulation of the colon and mesentery. This notion is gaining considerable attention, especially in the era of growing obese population among surgical patients. A totally laparoscopic approach is thought to minimise traction injuries and risk of micro-lacerations when exteriorising the bowel through thicker abdominal walls, which is known to worsen the outcome in bowel anastomosis ${ }^{[5,17]}$. However, the paucity in research is reflected by the fact that only one study, Vignali et al. ${ }^{[12]}, 2018$, was dedicated to a direct comparison between IA with EA in obese population, which did not demonstrate significant difference between the two groups in terms of perioperative outcomes, except for the lower incidence of incisional hernia in the IA group. Further studies are thus warranted to validate this notion, which would be valuable for evidence-based safe surgical practice in an obese population.

In addition, there are two growing areas of interest for which IA could provide superior outcomes, robotic surgery and patients undergoing emergency colectomy. A 2020 meta-analysis by Genova et al. ${ }^{[38]}$ showed that robotic right colectomy is superior to the laparoscopic approach in terms of length of stay, time to first flatus, and overall rate of complications. Part of this difference was attributed to the rate of IA in robotic colectomy, which was 10 times higher than in laparoscopic colectomy, and when a subgroup analysis was carried out for EA in both groups, the advantages of robotic colectomy disappeared, suggesting that IA may be a strong reason for superior outcome. Di Saverio et al. ${ }^{[39]}$ recently published a case series of 59 emergent laparoscopic colectomies with intracorporeal anastomosis, showing that such a technique is feasible and likely safe in acute surgery. The case series demonstrated an anastomotic leak rate of $3.4 \%$ and a reintervention rate of $3.4 \%$, both of which are comparable to the data found by this meta-analysis. This is a novel area that warrants further research.

However, this analysis should not be taken at its face value as it is not without limitations on closer inspection. In terms of the secondary outcomes, the data collected by the studies included in this metaanalysis are overall substantially heterogeneous, making it challenging to draw robust conclusions. The lack of standardised experimental conditions is likely to have impacted on the clinical outcome measures. For example, Anania et al. ${ }^{[15]}$ reported that the authors did not standardise the surgical steps of extracorporeal anastomosis in right hemicolectomy, although the intracorporal technique was uniform. Additionally, it is unclear whether some of the peri-operative measures known to improve patient outcomes were implemented. For example, it was unknown if the ERAS (enhanced-recovery-after-surgery) protocol, preoperative bowel preparation, or prophylactic antibiotics were administered. 
Therefore, we suggest that prudential interpretation around clinical significance rather than statistical significance is considered. Most available studies included in our analysis are merely observational without randomisation and are of retrospective design, the quality of which was assessed to be not very high based on IHE assessment.

In conclusion, this systematic review and meta-analysis on the comparative studies between IA and EA in laparoscopic colectomies has demonstrated IA can be safely considered by laparoscopic surgeons for resection of benign and malignant pathology in right and left colon without compromising oncological radicality. However, various limitations in the current data identified by this study need to be addressed by high-quality randomised trials involving longer follow-up.

\section{DECLARATIONS}

\section{Authors' contributions}

Study conception and design, data acquisition: Park SSW, Smith S

Data analysis and interpretation, drafting the article, critical revision of article, final approval of manuscript: Park SSW, Feng D, Smith S

\section{Availability of data and materials}

Not applicable.

\section{Financial support and sponsorship}

None.

\section{Conflicts of interest}

All authors declared that there are no conflicts of interest.

\section{Ethical approval and consent to participate}

Not applicable.

\section{Consent for publication}

Not applicable.

\section{Copyright}

(c) The Author(s) 2020.

\section{REFERENCES}

1. Feroci F, Lenzi E, Garzi A, Vannucchi A, Cantafio S, Scatizzi M. Intracorporeal versus extracorporeal anastomosis after laparoscopic right hemicolectomy for cancer: a systematic review and meta-analysis. Int J Colorectal Dis 2013;28:1177-86.

2. World Health Organization. Cancer Geneva: World Health Organization; 2018. Available from: https://www.who.int/news-room/factsheets/detail/cancer. [Last accessed on 2 Nov 2020]

3. Wu Q, Jin C, Hu T, Wei M, Wang Z. Intracorporeal versus extracorporeal anastomosis in laparoscopic right colectomy: a systematic review and meta-analysis. J Laparoendosc Adv Surg Tech A 2017;27:348-57.

4. Ricci C, Casadei R, Alagna V, et al. A critical and comprehensive systematic review and meta-analysis of studies comparing intracorporeal and extracorporeal anastomosis in laparoscopic right hemicolectomy. Langenbecks Arch Surg 2017;402:417-27.

5. Carnuccio P, Jimeno J, Pares D. Laparoscopic right colectomy: a systematic review and meta-analysis of observational studies comparing two types of anastomosis. Tech Coloproctol 2014;18:5-12.

6. Cirocchi R, Trastulli S, Farinella E, et al. Intracorporeal versus extracorporeal anastomosis during laparoscopic right hemicolectomy systematic review and meta-analysis. Surg Oncol 2013;22:1-13.

7. Milone M, Elmore U, Di Salvo E, et al. Intracorporeal versus extracorporeal anastomosis. Results from a multicentre comparative study on 512 right-sided colorectal cancers. Surg Endosc 2015;29:2314-20.

8. Iorio T, Blumberg D. A case-control study examining the benefits of laparoscopic colectomy using a totally intracorporeal technique for 
left-sided colon tumors. Surg Laparosc Endosc Percutan Tech 2014;24:381-4.

9. Kayaalp C, Kutluturk K, Yagci MA, Ates M. Laparoscopic right-sided colonic resection with transluminal colonoscopic specimen extraction. World J Gastrointest Endosc 2015;7:1078-82.

10. Rahbari NN, Weitz J, Hohenberger W, et al. Definition and grading of anastomotic leakage following anterior resection of the rectum: a proposal by the International Study Group of Rectal Cancer. Surgery 2010;147:339-51.

11. Wan X, Wang W, Liu J, Tong T. Estimating the sample mean and standard deviation from the sample size, median, range and/or interquartile range. BMC Med Res Methodol 2014;14:135.

12. Vignali A, Elmore U, Lemma M, Guarnieri G, Radaelli G, Rosati R. Intracorporeal versus extracorporeal anastomoses following laparoscopic right colectomy in obese patients: a case-matched study. Dig Surg 2018;35:236-42

13. Vignali A, Bissolati M, De Nardi P, Di Palo S, Staudacher C. Extracorporeal vs. intracorporeal ileocolic stapled anastomoses in laparoscopic right colectomy: an interim analysis of a randomized clinical trial. J Laparoendosc Adv Surg Tech A 2016;26:343-8.

14. Allaix ME, Degiuli M, Bonino MA, et al. Intracorporeal or extracorporeal ileocolic anastomosis after laparoscopic right colectomy: a double-blinded randomized controlled trial. Ann Surg 2019;270:762-7.

15. Anania G, Santini M, Scagliarini L, et al. A totally mini-invasive approach for colorectal laparoscopic surgery. World J Gastroenterol 2012;18:3869-74.

16. Biondi A, Santocchi P, Pennestrì F, Santullo F, D’Ugo D, Persiani R. Totally laparoscopic right colectomy versus laparoscopically assisted right colectomy: a propensity score analysis. Surg Endosc 2017;31:5275-82.

17. Chaves JA, Idoate CP, Fons JB, et al. A case-control study of extracorporeal versus intracorporeal anastomosis in patients subjected to right laparoscopic hemicolectomy. Cir Esp 2011;89:24-30.

18. Jian-Cheng T, Shu-Sheng W, Bo Z, Jian F, Liang Z. Total laparoscopic right hemicolectomy with 3-step stapled intracorporeal isoperistaltic ileocolic anastomosis for colon cancer: an evaluation of short-term outcomes. Medicine (Baltimore) 2016;95:e5538.

19. Erguner I, Aytac E, Baca B, Hamzaoglu I, Karahasanoglu T. Total laparoscopic approach for the treatment of right colon cancer: a technical critique. Asian J Surg 2013;36:58-63.

20. Fabozzi M, Allieta R, Brachet Contul R, et al. Comparison of short- and medium-term results between laparoscopically assisted and totally laparoscopic right hemicolectomy: a case-control study. Surg Endosc 2010;24:2085-91.

21. Franklin ME Jr, Gonzalez JJ Jr, Miter DB, et al. Laparoscopic right hemicolectomy for cancer: 11-year experience. Rev Gastroenterol Mex 2004;69 Suppl 1:65-72.

22. Grams J, Tong W, Greenstein AJ, Salky B. Comparison of intracorporeal versus extracorporeal anastomosis in laparoscopic-assisted hemicolectomy. Surg Endosc 2010;24:1886-91.

23. Hanna MH, Hwang GS, Phelan MJ, et al. Laparoscopic surgery for inflammatory bowel disease: a nationwide analysis of trends and outcomes. Surg Endosc Other Interventional Tech 2015;1:S330.

24. Hellan M, Anderson C, Pigazzi A. Extracorporeal versus intracorporeal anastomosis for laparoscopic right hemicolectomy. JSLS 2009;13:312-7.

25. Lee KH, Ho J, Akmal Y, Nelson R, Pigazzi A. Short- and long-term outcomes of intracorporeal versus extracorporeal ileocolic anastomosis in laparoscopic right hemicolectomy for colon cancer. Surg Endosc 2013;27:1986-90.

26. Magistro C, Lernia SD, Ferrari G, et al. Totally laparoscopic versus laparoscopic-assisted right colectomy for colon cancer: is there any advantage in short-term outcomes? A prospective comparative assessment in our center. Surg Endosc 2013;27:2613-8.

27. Marchesi F, Pinna F, Percalli L, et al. Totally laparoscopic right colectomy: theoretical and practical advantages over the laparo-assisted approach. J Laparoendosc Adv Surg Tech A 2013;23:418-24.

28. Mari GM, Crippa J, Costanzi ATM, et al. Intracorporeal anastomosis reduces surgical stress response in laparoscopic right hemicolectomy: a prospective randomized trial. Surg Laparosc Endosc Percutan Tech 2018;28:77-81.

29. Milone M, Angelini P, Berardi G, et al. Intracorporeal versus extracorporeal anastomosis after laparoscopic left colectomy for splenic flexure cancer: results from a multi-institutional audit on 181 consecutive patients. Surg Endosc 2018;32:3467-73.

30. Roscio F, Bertoglio C, De Luca A, Frattini P, Scandroglio I. Totally laparoscopic versus laparoscopic assisted right colectomy for cancer. Int J Surg 2012;10:290-5.

31. Scatizzi M, Kröning KC, Borrelli A, Andan G, Lenzi E, Feroci F. Extracorporeal versus intracorporeal anastomosis after laparoscopic right colectomy for cancer: a case-control study. World J Surg 2010;34:2902-8.

32. Shapiro R, Keler U, Segev L, Sarna S, Hatib K, Hazzan D. Laparoscopic right hemicolectomy with intracorporeal anastomosis: short- and long-term benefits in comparison with extracorporeal anastomosis. Surg Endosc 2016;30:3823-9.

33. Swaid F, Sroka G, Madi H, Shteinberg D, Somri M, Matter I. Totally laparoscopic versus laparoscopic-assisted left colectomy for cancer: a retrospective review. Surg Endosc 2016;30:2481-8.

34. Vergis AS, Steigerwald SN, Bhojani FD, Sullivan PA, Hardy KM. Laparoscopic right hemicolectomy with intracorporeal versus extracorporeal anastamosis: a comparison of short-term outcomes. Can J Surg 2015;58:63-8.

35. (IHE) IoHE. Quality Appraisal of Case Series Studies Checklist. 2014. Available from: http://www.ihe.ca/research-programs/rmd/cssqac/ cssqac-about. [Last accessed on 2 Nov 2020]

36. Hanna MH, Hwang GS, Phelan MJ, et al. Laparoscopic right hemicolectomy: short- and long-term outcomes of intracorporeal versus extracorporeal anastomosis. Surg Endosc 2016;30:3933-42

37. Singh R, Omiccioli A, Hegge S, McKinley C. Does the extraction-site location in laparoscopic colorectal surgery have an impact on incisional hernia rates? Surg Endosc 2008;22:2596-600.

38. Genova P, Pantuso G, Cipolla C, et al. Laparoscopic versus robotic right colectomy with extra-corporeal or intra-corporeal anastomosis: a 
systematic review and meta-analysis. Langenbeck Arch Surg 2020; doi: 10.1007/s00423-020-01985-x.

39. Di Saverio S, Birindelli A, Mandrioli M, Podda M, Binda GA. Intracorporeal anastomoses in emergency laparoscopic colorectal surgery from a series of 59 cases: where and how to do it - a technical note and video. Colorectal Dis 2017;19:0103-7. 